\title{
Oral Health-Related Quality of Life After Gastric Bypass Surgery
}

\author{
Negin Taghat ${ }^{1}$ (I) $\cdot$ Malin Werling ${ }^{2} \cdot$ Anna-Lena Östberg $^{1,3}$
}

Published online: 12 October 2019

(C) The Author(s) 2019

\begin{abstract}
Objective The aim was to examine how individuals treated for obesity with gastric bypass (GBP) surgery perceived their oral health and oral health-related quality of life (OHRQoL).

Method All individuals in one Swedish region who had undergone GBP surgery $(n=1182)$ were sent a postal questionnaire 2 years after surgery. The questionnaire comprised items on sociodemographics, oral symptoms and the Oral Health Impact Profile-49 to assess the OHRQoL.

Results The mean age was 47.6 years with $75 \%$ females, response rate $55.3 \%$. The self-perceived oral health was rated low by $45 \%$ of the respondents. Gender differences were seen, for instance, regarding hypersensitive teeth (men 18.8\%, women 30.8\%, $p=0.003$ ). Nine out of ten reported at least one oral impact experienced sometimes, fairly or very often, according to the Oral Health Impact Profile-49 (OHIP-49). The mean additive OHIP-49 score was 30.3 (SD 36.1). The associations between selfreported oral health and OHRQoL were consistent throughout. Tooth hypersensitivity generated an OR of 2.28 (95\% CI $2.28-$ 8.46) of having $\geq 2$ impacts on OHRQoL.

Conclusion A large proportion of individuals having undergone GBP surgery reported problems with their oral health and impacts on their OHRQoL, indicating a need for medical and dental staff-surgeons and general practitioners as well as other health professionals - to offer oral health promotion and prevention measures.
\end{abstract}

Keywords Bariatric surgery $\cdot$ Oral health $\cdot$ Quality of life

\section{Introduction}

The prevalence of obesity is rising steadily and in 2016, $30 \%$ of the world's adult population were overweight (Body Mass Index $(\mathrm{BMI}) \geq 25 \mathrm{~kg} / \mathrm{m}^{2}$ ) and $13 \%$ were obese $\left(\mathrm{BMI} \geq 30 \mathrm{~kg} / \mathrm{m}^{2}\right)[1]$. In Sweden, the corresponding proportions at the time were $36 \%$ and $15 \%$, respectively [2].

Negin Taghat

negin.taghat@gu.se

Malin Werling

Malin.werling@gmail.com

Anna-Lena Östberg

anna-lena.ostberg@vgregion.se

1 Department of Behavioral and Community Dentistry, Institute of Odontology, The Sahlgrenska Academy, University of Gothenburg, Gothenburg, Sweden

2 Department of Gastrosurgical Research and Education, Sahlgrenska Academy, University of Gothenburg, Gothenburg, Sweden

3 Public Dental Service, Region Västra Götaland, Sweden
Obesity causes several health problems in those affected, with higher morbidity and mortality rates than in the general population [3, 4]. Quality of life is often reduced in obese individuals with poor physical and mental health, as well as social disabilities due to their weight [5]. In the oral cavity, obesity has also shown associations to periodontal disease and tooth loss [6-8].

Surgical treatment of morbid obesity is an effective method $[9,10]$ leading to long-term significant weight loss as well as reduced comorbidity and mortality rates [11]. However, bariatric surgery may be associated with both short- and long-term complications [10, 12]. In Sweden, laparoscopic gastric bypass (GBP) [10] surgery has hitherto been the procedure most commonly used [13] with the overall complication frequency around $8 \%$ in 2016 while long-term complications were estimated to be present in about $7 \%$ [13].

Oral complications arising from bariatric surgery are still sparsely studied. Published studies are often based on a mixed study population including outdated surgical procedures which make it difficult to apply the results to today's patients. However, some findings from studies with short 
follow-up periods after GBP surgery indicate an increased risk of tooth hypersensitivity, deeper periodontal pockets, and dental caries [14-17], although contradictory findings have also been reported $[18,19]$. Likewise, a recent systematic review by Salgado-Pervalo et al. found inconclusive results with regard to bariatric surgery as a risk factor for caries development [20]. Cardozo et al. reported increased salivary flow rate with less dry mouth sensation after GBP surgery, which was discussed as an effect of reduced medication [19].

Improvements in the general health-related quality of life have been found after bariatric surgery [21]. These improvements followed shortly after surgery, correlated to initial weight loss and remained high in the long term. However, patients treated with bariatric surgery show poorer quality of life than the general population over time [21]. Little is known about the impact on the oral health-related quality of life (OHRQoL) [14]. Potential problems may include physical, psychological as well as social aspects, such as pain, speech difficulties, embarrassment due to ill-fitting dental prostheses, or feelings of shame about the appearance of one's teeth [22]. There is a need to include the patient perspective and assess the oral effects and the OHRQoL in individuals after bariatric surgery. The aim of this study was therefore to examine how individuals treated with GBP surgery perceived their oral health and OHRQoL.

\section{Material and Methods}

\section{Study Sample}

The sample comprised all individuals who had undergone GBP surgery in the Region of Västra Götaland, Sweden, during $2011(n=1215)$. One-sixth of the Swedish population resides in the region, which includes both rural and urban areas. The study was approved by the Research Ethics Committee of Gothenburg University (reg. no. 057-14). Based on the approval, the Scandinavian Surgery Obesity Registry (SOReg), a national quality registry for bariatric surgery in Sweden, provided contact information for the individuals in the sample [13]. The advisory board of the SOReg assessed the study independently in accordance with their standard procedures. All participants signed an informed consent form.

\section{Data Collection}

A postal questionnaire was distributed in September 2014, just over 2 years after surgical treatment to allow for enough time to have elapsed for stabilization of weight loss, dietary habits and general short-term complications. Non-respondents were sent a reminder after 2 weeks. Questionnaires without consent were discarded $(n=8)$ (Fig. 1$)$.

\section{Variables and Instruments}

The questionnaire comprised questions regarding demographic and socioeconomic characteristics, together with healthrelated variables. The demographic variables were gender and age (21-39 years/40-59 years/ $\geq 60$ years). Socioeconomics was represented by educational level ( $>$ compulsory school vs. compulsory school or less $\leq 9$ years) and marital status (cohabiting vs. not cohabiting).

The participants reported their current self-perceived oral health (very good/good vs. rather bad/bad/very bad), selfassessed number of teeth $(\geq 20$ remaining teeth vs. $<20$ remaining teeth/edentulous) and chewing ability (without difficulty vs. difficult/unable). Oral health habits were mirrored by the frequency of dental appointments during the last 5 years (regularly/at least once a year/3-4 appointments vs. 1-2 appointments/never), and the reason for the participant's last dental visit (routine examination vs. pain/other problem). The participants were also asked about perceived oral health problems before the surgical intervention (sometimes/seldom/ never vs. very often/fairly often). Perceived oral symptoms included tooth hypersensitivity, acid reflux episodes and vomiting episodes (never/a few times a year vs. a few times a month/a few times a week/daily).

OHRQoL was assessed using the Swedish version of the Oral Health Impact Profile-49 (OHIP-49) instrument [22, 23], containing forty-nine items in seven domains: functional limitation (9 items), physical discomfort (9 items), physical disability (9 items), psychosocial discomfort (5 items), psychosocial disability (6 items), social disability ( 5 items), and handicap (6 items). Each item begins with the phrase 'Over the past year, how often have you experienced (...) because of

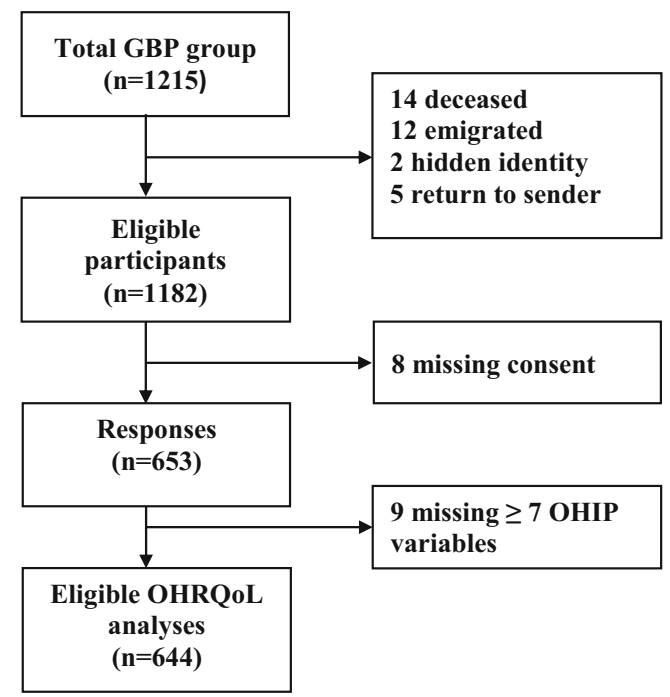

Fig. 1 Flow chart. Inclusion of participants 
problems with your teeth, mouth, dentures or jaws?'. The response options were 'never' (0), 'hardly ever' (1), 'occasionally' (2), 'fairly often' (3) and 'very often' (4).

Calculation of the derived OHIP scores was made in two ways [24]. The first method was the additive method (OHIPADD), where scores for all items were summed up, giving a possible range from 0 to $196(4 \times 49)$. The simple count method (OHIP-SC) was the second method, where items answered with 'very often', 'fairly often' and 'occasionally' were given the value 1 , and the answers 'hardly ever' and 'never' were given the value 0 . The scores were summed up, giving a possible range of $0-49$. For both methods, higher scores correspond to a greater impact on OHRQoL.

\section{Statistical Analysis}

Management of data and analyses were carried out in the SPSS (Statistical Package for Social Sciences) version 22.0 (IBM Corporation, Armonk, NY, USA). Descriptive statistics were used for demographic data, including mean values, standard deviations and ranges. Forms with $\geq 7$ missing answers in the OHIP items were excluded from the data analysis of the OHIP $(n=9)$. In forms with missing information in 1-7 OHIP items, imputation was performed using the case mean substitution technique [25]. Differences in the proportions and distribution of scores were examined using the chi-square test and the Mann-Whitney $U$ test. Correlations between the subscales in the OHIP were assessed using Spearman's rank correlation. Cronbach's alpha was used to test the internal consistency of all scales.

The associations between oral health variables and the OHIP, including the impact of possible confounders, were explored with bivariate and multivariate logistic regression analyses. For the analyses, the OHIP-SC was dichotomized into 'having at least two impacts' vs. 'one or no impact'. The OHIP-ADD was dichotomized at the median value $(\geq$ median vs. $<$ median).

\section{Results}

Of the 1215 subjects according to the SOReg, 14 were deceased, 12 had emigrated and two had protected identities precluding contact. Five questionnaires were returned to sender for unknown recipient reasons. A total of 1182 postal questionnaires were sent out. After control for written consent, 653 (55.3\%) forms remained for the analyses.

The sociodemographic characteristics of the participants are presented by gender in Table 1 .

The mean age of the participants was 47.6 years (SD 12.0), that is, slightly higher than in the total sample of 1182 GBP patients (44.3 years, SD 11.8). The gender distribution in the total sample and among participants was similar with the majority being women (75\%). Most participants were cohabiting
(65\%) and had an education above compulsory school level $(80.3 \%)$. No statistically significant gender differences were found in the sociodemographics.

Table 2 shows gender-specific characteristics in selfreported oral health, oral health status, symptoms and habits as stated by the participants 2 years after GBP surgery. About one of ten participants reported that they had had oral health problems 'often' or 'very often' prior to GBP surgery. Their current self-perceived oral health was rated as less good, with about $45 \%$ reporting very bad, bad or average oral health.

A greater proportion of men reported a larger number of missing teeth $(p=0.020)$ and infrequent visits to the dentist $(p \leq 0.001)$, compared with women. One-fourth reported chewing problems (NS between genders). A sub-analysis revealed that having less than 20 teeth was significantly related to chewing problems (not in tables): $60 \%$ of those with $<20$ teeth but only $18 \%$ of those with $\geq 20$ teeth $(p<0.001)$. The most frequent problem was tooth hypersensitivity, with women $(30.8 \%)$ reporting more problems than men $(18.8 \%, p=$ $0.003)$. The participants had moderate problems with acid reflux (16.1\%) and minor problems with vomiting episodes (8.9\%) (NS between genders).

The OHIP-49 (add and single count) scales along with scales for the different dimensions/subscales and internal consistencies are presented in Table 3.

Almost 4 out of 5 participants (78.9\%) reported at least one oral impact occasionally, fairly often or very often, with no difference between genders. Only 54 individuals $(8.4 \%)$ reported no impact at all (not in table). The mean OHIP-ADD was 30.3 (SD 36.1); however, for the $1 / 5$ of individuals reporting the most impact (not in table), the mean score was 91.4 (SD 32.3) to be related to the possible max score of 196. The mean OHIP-SC49 was 15.6 (SD 14.6) (max score 49).

The OHIP dimensions with the highest reported impact were functional limitation and physical pain $(\geq$ $80 \%$ ), while more than half of the participants reported impacts in the dimensions of physiological discomfort and physical disability. In the subscale 'physical pain', women scored significantly higher than men (any impact, $86.3 \%$ vs. $78.7 \%, p=0.021$ ). However, men reported significantly more social disability than women (any impact, $43.1 \%$ vs. $32.3 \%, p=0.043$ ). There were no significant differences between the three age groups in the subscale scores. All scales and subscales displayed high internal consistency, with all Cronbach's alpha values $>0.8$ (Table 3 ).

Table 4 presents the matrix of correlations between the OHIP subscales, with all $r>0.5$.

The highest correlations were seen between social disability and psychological disability and between psychological disability and physical disability. The social disability dimension generated the weakest correlations to functional limitation and physical pain. 
Table 1 Characteristics of the study population, individuals having undergone GBP surgery $\geq$ 2 years ago, by gender

\begin{tabular}{lllll}
\hline & & Men & Women & \\
& & $n=161(24.7 \%)$ & \\
& & & \\
& & $49.1(12.9)$ & $472(75.3 \%)$ & \\
\hline Age & Years & $37(23.4)$ & $128(26.3)$ & 0.230 \\
Age strata & $21-39$ years & $81(51.3)$ & $273(56.2)$ & 0.070 \\
& 40-59 years & $40(25.3)$ & $85(17.5)$ & 0.812 \\
Marital status & $\geq 60$ years & $98(61.2)$ & $339(68.9)$ & 0.432 \\
\multirow{2}{*}{ Education } & Married/cohabitant & $62(38.2)$ & $153(31.1)$ & 0.074 \\
& Unmarried/not cohabitant & $124(77.5)$ & $404(83.1)$ & 0.110 \\
& $\geq$ Compulsory school & $36(22.5)$ & $82(16.9)$ & \\
\hline
\end{tabular}

Age mean (SD), numbers and percentages. Missing cases $0.2-1.4 \%$
The single-item variables were used as independent variables in bivariate and multivariate logistic regression analyses with the OHIP-SC dichotomized into ' $\geq 2$ or more impacts' vs. 'less' and the OHIP-ADD dichotomized at the median value as dependent variables (Table 5). In the multivariate analyses, adjustments were made for age, gender and socioeconomics (educational level and marital status). An overall pattern with positive associations was revealed, with the strongest associations between chewing ability and the OHIP-SC (adjusted OR 7.93, 95\% CI 3.39-18.6) as well as the OHIPADD (adjusted OR 16.3, 95\% CI 9.06-29.2). Current selfperceived oral health and the reason for the most recent dental visit were also strongly associated with both the OHIP-SC and the OHIP-ADD. The only non-significant associations in both crude and adjusted analyses were between dental visit habits and the OHIP-SC. Also, the association between reported problems before GBP surgery and the OHIP-SC was attenuated by the adjustments applied (age, gender and socioeconomics).

When all the independent variables in the bivariate analyses, together with the possible confounders of age, gender and socioeconomics, were included in a multivariate model, only three explanatory variables were identified as statistically significant for the probability of having impacts as measured with the OHIP-SC. These were self-perceived oral health (OR 3.52, 95\% CI 1.87-6.66), reason for dental visit (OR $2.26,95 \%$ CI 1.08-4.70) and tooth hypersensitivity (OR $2.43,95 \%$ CI 1.18-5.04). In the corresponding analyses, using the OHIP-ADD as the outcome, four statistically significant explanatory variables were identified: self-perceived oral health (OR 3.44, 95\% CI 2.16-5.48), reason for dental visit (OR 2.70, 95\% CI 1.60-4.55), tooth hypersensitivity (OR $3.38,95 \%$ CI 1.98-5.76) and chewing ability (OR 5.77, 95\% CI 2.72-12.22) (not in tables).

Table 2 Self-reported oral health, oral health habits and symptoms stated in questionnaires by participants having undergone GBP surgery $\geq 2$ years ago. $p$ values denoting gender differences

\begin{tabular}{|c|c|c|c|c|}
\hline Variable & Rating & $\begin{array}{l}\text { Men } \\
n(\%)\end{array}$ & $\begin{array}{l}\text { Women } \\
n(\%)\end{array}$ & $p$ value \\
\hline \multicolumn{5}{|l|}{ Self-perceived oral health } \\
\hline Stated oral health problems prior to surgery & Often/very often & $15(9.4)$ & $41(8.4)$ & 0.709 \\
\hline Current self-perceived oral health & Average/bad/very bad & $71(44.7)$ & $217(44.5)$ & 0.967 \\
\hline \multicolumn{5}{|l|}{ Oral health status } \\
\hline Number of remaining teeth & $\leq 19$ remaining teeth & $37(23.0)$ & $73(15.0)$ & 0.020 \\
\hline Chewing ability & With caution/not at all & $48(29.8)$ & $115(23.5)$ & 0.107 \\
\hline \multicolumn{5}{|l|}{ Oral symptoms } \\
\hline Tooth hypersensitivity & A few times a month/a few times a week/daily & $30(18.8)$ & $149(30.8)$ & 0.003 \\
\hline Acid reflux & A few times a month/a few times a week/daily & $21(13.2)$ & $83(17.0)$ & 0.258 \\
\hline Vomiting & A few times a month/a few times a week/daily & $12(7.6)$ & $45(9.4)$ & 0.501 \\
\hline \multicolumn{5}{|l|}{ Dental care habits } \\
\hline Dental visits last 5 years & 1-2 appointments/never & $52(32.7)$ & $90(18.6)$ & $\leq 0.001$ \\
\hline Reason for last dental visit & Pain/other problems & $53(33.8)$ & $155(33.3)$ & 0.922 \\
\hline
\end{tabular}

Data are numbers and percentages

Missing cases $0.3-4.7 \%$ 
Table 3 Oral Health Impact Profile (OHIP-49) and subscales. Numbers and percentages of participants having undergone GBP surgery $\geq 2$ years ago and stating impacts. Internal reliability of scales/subscales measured with Cronbach's $\alpha$

\begin{tabular}{lllll}
\hline & & Mean (SD) & Impact $n(\%)$ & Cronbach's $\alpha$ \\
\hline OHIP-ADD 49 & & $30.3(36.1)$ & $590(91.6)^{*}$ & 0.981 \\
OHIP-SC 49 & & $15.6(14.6)$ & $514(78.7)^{* *}$ & 0.974 \\
OHIP-49 subscales & Subscale (no of items) & Any impact*n $(\%)$ & \\
& Functional limitation (9) & $6.8(6.7)$ & $557(86.0)$ & 0.860 \\
& Physical pain (9) & $7.4(7.4)$ & $534(82.9)$ & 0.912 \\
& Psychological discomfort (9) & $3.7(5.3)$ & $348(53.9)$ & 0.942 \\
& Physical disability (5) & $4.2(6.4)$ & $370(57.5)$ & 0.913 \\
& Psychological disability (5) & $3.6(5,6)$ & $300(46.6)$ & 0.945 \\
& Social disability (5) & $1.9(3.6)$ & $226(35.0)$ & 0.911 \\
& Handicap (6) & $2.7(5.0)$ & $268(41.5)$ & 0.930 \\
\hline
\end{tabular}

OHIP-ADD 49: number of individuals with any impact; OHIP-SC: number of individuals with impacts 'very often/fairly often/occasionally'

*Any impact 'very often/fairly often/occasionally/hardly ever'. Missing cases $0.8-1.4 \%$

**Any impact 'very often/fairly often/occasionally'. Missing cases $1.4 \%$

\section{Discussion}

The majority of the participants in the study having undergone GBP surgery reported problems with their oral health. The most frequent subjective problems were difficulty chewing and tooth hypersensitivity. The majority experienced impact on their oral health-related quality of life with many of them reporting physical pain.

A strength of the study was that the sample comprised all individuals who had undergone GBP surgery in a large region of Sweden during an entire year. The response rate was modest (55.3\%), however, corresponding with recent similar studies [26]. The topic may have been perceived as sensitive [27]. For instance, feelings of guilt could be evoked if the person failed to adhere to post-op recommendations about diet. Possibly, those with a strong commitment or those with special health problems might also be more inclined to answer. On the other hand, people with no mouth problems may have refrained from responding because they considered the topic uninteresting. Another plausible reason for not responding could be survey response fatigue [28]. Ethical reasons precluded approaching non-responders; however, the age and gender distribution was similar in the drop-out group as in the total sample. The greater proportion of women in the sample is consistent with previous studies, showing that more women than men undergo GBP surgery [29].

The study made use of well-validated questions and instruments $[22,23,30]$. The design with a self-reported form did entail a risk of memory bias and social desirability; that is, respondents might portray themselves in a more positive or more negative light [31]. The oral clinical implications of bariatric surgery were not examined in the study and need to be further investigated, preferably with a longitudinal design. The current adipose status, total weight loss and nutritional status would then be of interest [6, 32]. A qualitative approach might also generate more profound knowledge about how individuals perceive their oral health after bariatric surgery [33].

The number of teeth is often used as a proxy for dental health $[34,35]$ and having few teeth $(<20)$ was related to chewing problems, which could be expected [36]. Selfreported symptoms from the mouth were common in the study, with hypersensitivity of the teeth as the main reported symptom. This condition is often caused by dental erosion with lost enamel [37], which, in turn, can be caused by acid reflux and/or vomiting [38]. These two symptoms were, however, less frequent in the study, which could be expected, as both symptoms decrease or even disappear after the rearrangement of the gastrointestinal tract during GBP surgery [39].
Table 4 Spearman's correlations among the 7 dimensions of the Oral Health Impact Profile (OHIP-49)

\begin{tabular}{lllllll}
\hline & $\begin{array}{l}\text { Functional } \\
\text { limitation }\end{array}$ & $\begin{array}{l}\text { Physical } \\
\text { pain }\end{array}$ & $\begin{array}{l}\text { Psychological } \\
\text { discomfort }\end{array}$ & $\begin{array}{l}\text { Physical } \\
\text { disability }\end{array}$ & $\begin{array}{l}\text { Psychological } \\
\text { disability }\end{array}$ & $\begin{array}{l}\text { Social } \\
\text { disability }\end{array}$ \\
\hline Functional limitation & - & & & & & \\
Physical pain & 0.797 & - & & & \\
Psychological discomfort & 0.782 & 0.780 & - & & & \\
Physical disability & 0.794 & 0.746 & 0.784 & - & - & \\
Psychological disability & 0.703 & 0.686 & 0.765 & 0.804 & - & \\
Social disability & 0.586 & 0.571 & 0.636 & 0.671 & 0.805 & 0.772 \\
Handicap & 0.692 & 0.661 & 0.752 & 0.725 & 0.799 & \\
\hline
\end{tabular}




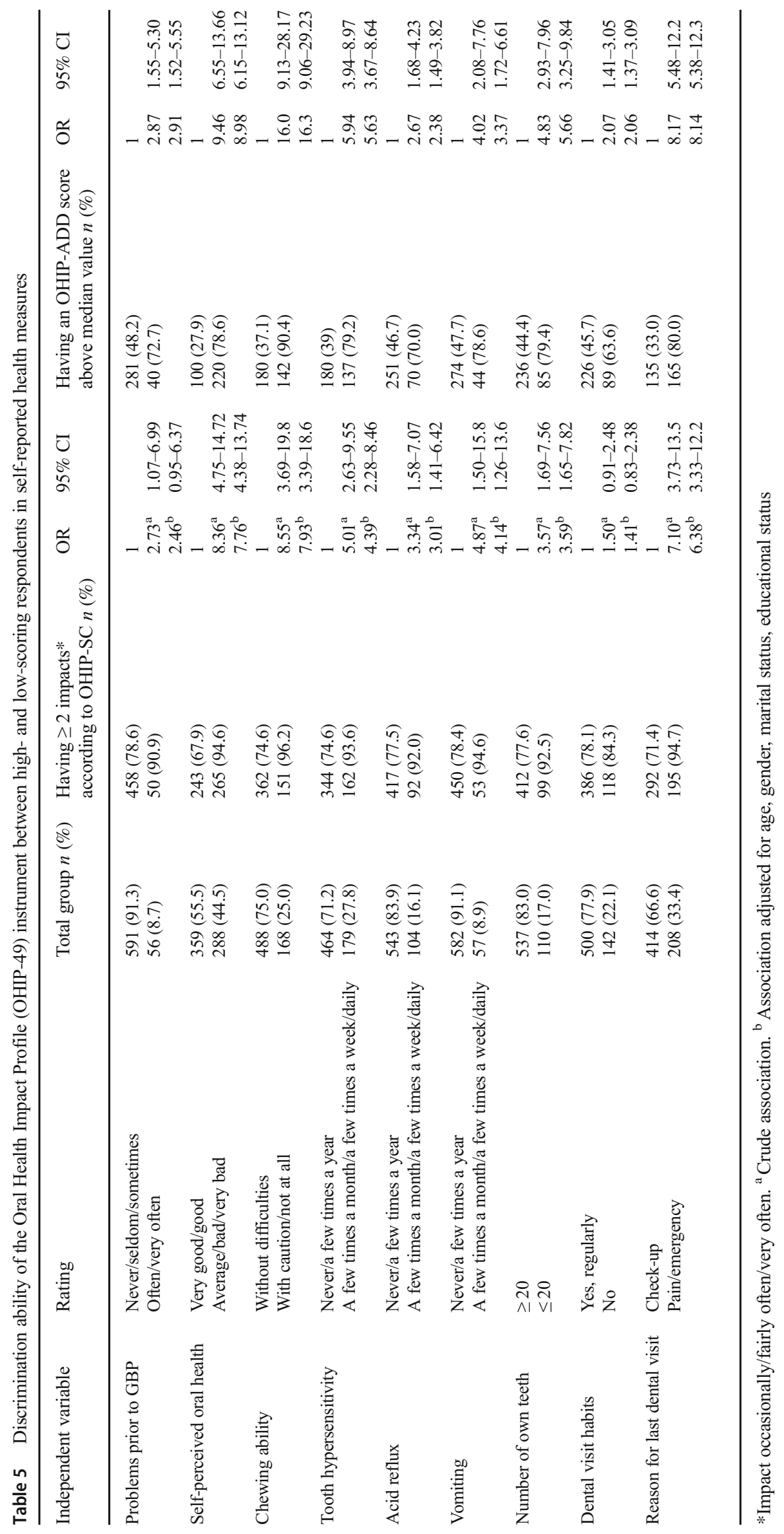


However, some individuals may still perceive problems and the findings are in line with those in an early paper by Heling et al. although their study included several bariatric surgical techniques [40]. A recent study showed that perhaps the treatment efficacy of GBP on reflux symptoms is overestimated, as many patients still require anti-reflux medication [41]. General causes for dental erosion can be excessive consumption of soft drinks with a low $\mathrm{pH}$ level [42]. This could possibly be part of an eating/drinking behaviour that was present prior to surgery [43]. Different eating disorders which make individuals gravitate towards high calorie/sugary foods are also known to be present in patients seeking bariatric surgery treatment [44].

As a whole, oral problems are likely to infer an impaired OHRQoL [23, 45]. A recent study could not verify associations between oral problems and OHRQoL in individuals having undergone bariatric surgery when inquiring a few items from the OHIP [46]. However, in our study using the full OHIP formula, most participants reported some impact on their OHRQoL. There was a positive skewedness with a large proportion reporting few impacts while a smaller group reported many impacts, similar to other studies [47, 48]. Sensitive individuals undergoing GBP surgery may develop more problems with their oral health and oral health-related quality of life. Also, all mean values in the seven subscales of OHIP were similar to the scores of subjects with malocclusion problems in a Swedish study that is statistically higher than in the general population [23]. Functional limitation and physical pain have often been the most frequently reported oral impacts in both patients and in the general population, akin to our findings $[22,23]$. It is noteworthy that these dimensions generated the lowest correlation coefficients in relation to social disability, indicating that despite perceived problems, the impact on the individual's social life might be a minor issue. Still, all interrelationships between the different dimensions were strong, which also validated the high internal reliability of the full OHIP scales.

The OHIP-ADD showed stronger associations with other variables than the OHIP-SC, with two exceptions, acid reflux and vomiting, which strengthens the reasoning about these two symptoms being less frequent after GBP surgery. Thus, the additive method was a more sensitive method for measuring the magnitude of oral health-related quality of life. The simple count method might be seen more as an indicator of whether an impact is present [47].

The significant variables for experiencing a lowered OHRQoL in the multivariate models-self-perceived oral health, reason for dental visits, tooth hypersensitivity and chewing ability — should be considered by both medical and dental staff-surgeons, general practitioners, dieticians, general dental practitioners, dental hygienists and others - when encountering GBP patients. The attenuation of the associations by the adjustments could be expected, as cohabitation and a high educational level often lower the risk of experiencing problems as a whole $[35,49]$.

Our results revealed some significant differences between genders. Men reported less favourable dental care habits with fewer dental visits and fewer remaining teeth than women. These findings are consistent with previous studies in Western countries [49]. A somewhat unexpected finding was that men reported more impacts in the OHIP dimension of social disability. This might be explained by obese men seeking medical care later and possibly have a higher BMI before GBP surgery than obese women [13, 50]. On the other hand, the female participants in our study more often reported tooth hypersensitivity and physical pain, which could be discussed in biological terms, as some studies show that women have greater pain perception than men [51]. Furthermore, it may be more acceptable for women to admit and express problems due to psychosocial expectations [52].

\section{Conclusion}

A large proportion of individuals having undergone GBP surgery reported problems with their oral health and impacts on their OHRQoL indicating a need for both medical and dental staff to offer oral health promotion and prevention measures.

Acknowledgments The Scandinavian Obesity Surgery Registry Study Group is acknowledged for providing contact information to the individuals in the sample. Open access funding provided by University of Gothenburg.

Funding Information The study was funded by the Local Research and Development Council Södra Älvsborg Sweden under Grant VGFOUSA394101, 402971, 489001, 490101, 602971.

Data Availability The datasets used and analysed during the current study are available from corresponding author on reasonable request.

\section{Compliance with Ethical Standards}

Conflict of Interest The authors declare that they have no conflicts of interest.

Ethics Statement The study was approved in accordance with the ethical standards of the Research Ethics Committee of Gothenburg University (reg. no. 057-14) and with the 1964 Helsinki declaration and its later amendments or comparable ethical standards.

Consent Statement Informed consent was obtained from all individual participants included in the study.

Disclaimer The funding body had no role in design, collection, analyses, interpretation of data or in writing the manuscript. 
Open Access This article is distributed under the terms of the Creative Commons Attribution 4.0 International License (http:// creativecommons.org/licenses/by/4.0/), which permits unrestricted use, distribution, and reproduction in any medium, provided you give appropriate credit to the original author(s) and the source, provide a link to the Creative Commons license, and indicate if changes were made.

\section{References}

1. World Health Organization [Internet]. Geneva: WHO; c2019. Obesity and overweight: 16 Feb 2018 [cited 2018 Feb 20] Available from: http://www.who.int/mediacentre/factsheets/fs311/en.

2. Folkhälsomyndigheten [The Public Health Agency of Sweden][Internet]. Stockholm: c2019. Övervikt och fetma [Overweight and Obesity]: 14 March 2019 [cited 15 June 2018]. Available from: https://www.folkhalsomyndigheten.se/ folkhalsorapportering-statistik/folkhalsans-utveckling/halsa/ overvikt-och-fetma.

3. Sjöström LV. Morbidity of severely obese subjects. Am J Clin Nutr. 1992;55(Suppl 2):508-15.

4. Whitlock G, Lewington S, Sherliker P, et al. Body-mass index and cause-specific mortality in 900000 adults: collaborative analyses of 57 prospective studies. Lancet. 2009;373:1083-96.

5. Ul-Haq Z, Mackay DF, Fenwick E, et al. Meta-analysis of the association between body mass index and health-related quality of life among adults, assessed by the SF-36. Obesity. 2013;21:322-7.

6. Östberg AL, Bengtsson C, Lissner L, et al. Oral health and obesity indicators. BMC Oral Health 2012 [cited 2017 Jan 03]:[7 p.]. https://doi.org/10.1186/1472-6831-12-50

7. Suvan J, D'Aiuto F, Moles DR, et al. Association between overweight/obesity and periodontitis in adults. A systematic review. Obes Rev. 2011;12:381-404.

8. Nascimento GG, Leite FR, Do LG, et al. Is weight gain associated with the incidence of periodontitis? A systematic review and metaanalysis. J Clin Periodontol. 2015;42:495-505.

9. Bray GA, Fruhbeck G, Ryan DH, et al. Management of obesity. Lancet. 2016;387:1947-56.

10. Colquitt JL, Pickett K, Loveman E, et al. Surgery for weight loss in adults. Cochrane Database Syst Rev. 2014 [cited 2017 Aug 18]: [126 p.]. https://doi.org/10.1002/14651858.CD003641.pub4

11. Sjöström L. Review of the key results from the Swedish Obese Subjects (SOS) trial - a prospective controlled intervention study of bariatric surgery. J Intern Med. 2013;273:219-34.

12. Melissas J, Stavroulakis K, Tzikoulis V, et al. Sleeve gastrectomy vs Roux-en-Y gastric bypass. Data from IFSO-European Chapter Center of Excellence Program. Obes Surg. 2017;27:847-55.

13. Scandinavian Obesity Surgery Registy [Internet]. SOReg; c2019 [uppdated 2019, cited 11 Feb 2018]. Available from: http://www. ucr.uu.se/soreg.

14. Marsicano JA, Grec PG, Belarmino LB, et al. Interfaces between bariatric surgery and oral health: a longitudinal survey. Acta Cir Bras. 2011;26(Suppl 2):79-83.

15. Marsicano JA, Sales-Peres A, Ceneviva R, et al. Evaluation of oral health status and salivary flow rate in obese patients after bariatric surgery. Eur J Dent. 2012;6:191-7.

16. Netto BD, Moreira EA, Patino JS, et al. Influence of Roux-en-Y gastric bypass surgery on vitamin $\mathrm{C}$, myeloperoxidase, and oral clinical manifestations: a 2-year follow-up study. Nutr Clin Pract. 2012;27:114-21

17. Sales-Peres SH, de Moura-Grec PG, Yamashita JM, et al. Periodontal status and pathogenic bacteria after gastric bypass: a cohort study. J Clin Periodontol. 2015;42:530-6.
18. Jaiswal GR, Jain VK, Dhodapkar SV, et al. Impact of bariatric surgery and diet modification on periodontal status: a six month cohort study. J Clin Diagn Res. 2015;9:43-5.

19. Cardozo DD, Hilgert JB, Hashizume LN, et al. Impact of bariatric surgery on the oral health of patients with morbid obesity. Obes Surg. 2014;24:1812-6.

20. Salgado-Peralvo AO, Mateos-Moreno MV, Arriba-Fuente L, et al. Bariatric surgery as a risk factor in the development of dental caries: a systematic review. Public Health. 2018;155:26-34.21.

21. Andersen JR, Aasprang A, Karlsen TI, et al. Health-related quality of life after bariatric surgery: a systematic review of prospective long-term studies. Surg Obes Relat Dis. 2015;11:466-73.

22. Slade GD, Spencer AJ. Development and evaluation of the Oral Health Impact Profile. Community Dent Health. 1994;11:3-11.

23. Larsson P, List T, Lundström I, et al. Reliability and validity of a Swedish version of the Oral Health Impact Profile (OHIP-S). Acta Odontol Scand. 2004;62:147-52.

24. Allen PF, Locker D. Do item weights matter? An assessment using the oral health impact profile. Community Dent Health. 1997;14:133-8.

25. Fox-Wasylyshyn SM, El-Masri MM. Handling missing data in selfreport measures. Res Nurs Health. 2005;28:488-95.

26. Davey AF, Roberts MJ, Mounce L, Maramba I, Campbell JL Testretest stability of patient experience items derived from the national GP patient survey. SpringerPlus 2016 [cited 2018 Jan 20]:[15 p.] Authors manuscript available at https:/www.ncbi.nlm.nih.gov/ pmc/articles/PMC5055510 PubMed Central; PMCID27795898.

27. Edwards P, Roberts I, Clarke M, et al. Increasing response rates to postal questionnaires: systematic review. BMJ. 2002[cited 2018 Jan 20]:[9 p.]. Article available at https://www.ncbi.nlm.nih.gov/ pmc/articles/PMC111107 PubMed Central; PMCID111107.

28. Porter SR, Whitcomb ME, Weitzer WH. Multiple surveys of students and survey fatigue. New Dir Inst Res. 2004;2004(121):63-73.

29. Kolotkin RL, Crosby RD, Gress RE, et al. Health and health-related quality of life: differences between men and women who seek gastric bypass surgery. Surg Obes Relat Dis. 2008;4:651-8.

30. Statistics Sweden [Internet]. Undersökningar av levnadsförhållanden: ULF [Living Conditions Surveys: ULF]. 1997. Available from: https:/www.scb.se/contentassets/ 0410d293ba614353870fdfa0e9e9a924/ulf9734.pdf.

31. Van de Mortel T. Faking it: social desirability response bias in selfreport research. Aust J Adv Nurs. 2008;25:40-8.

32. Chapple IL, Bouchard P, Cagetti MG, et al. Interaction of lifestyle, behavior or systemic diseases with dental caries and periodontal diseases: consensus report of group 2 of the joint EFP/ORCA workshop on the boundaries between caries and periodontal diseases. J Clin Periodontol. 2017;44(Suppl 18):39-51.

33. Lier HO, Aastrom S, Rortveit K. Patients' daily life experiences five years after gastric bypass surgery-a qualitative study. J Clin Nurs. 2016;25:322-31.

34. Östberg AL, Nyholm M, Gullberg B, et al. Tooth loss and obesity in a defined Swedish population. Scand J Public Health. 2009;37:427-33.

35. Åström AN, Gulcan F, Ekbäck G, et al. Long-term healthy lifestyle patterns and tooth loss studied in a Swedish cohort of middle-aged and older people. Int J Dent Hyg. 2015;13:292-300.

36. Naka O, Anastassiadou V, Pissiotis A. Association between functional tooth units and chewing ability in older adults: a systematic review. Gerodontology. 2014;31:166-77.

37. Bartlett D, Ganss C, Lussi A. Basic Erosive Wear Examination (BEWE): a new scoring system for scientific and clinical needs. Clin Oral Investig. 2008;12(Suppl 1):65-8.

38. Kanzow P, Wegehaupt FJ, Attin T, et al. Etiology and pathogenesis of dental erosion. Quintessence Int. 2016;47:275-8.

39. Madalosso CA, Gurski RR, Callegari-Jacques SM, et al. The impact of gastric bypass on gastroesophageal reflux disease in morbidly obese patients. Ann Surg. 2016;263:110-6. 
40. Heling I, Sgan-Cohen HD, Itzhaki M, et al. Dental complications following gastric restrictive bariatric surgery. Obes Surg. 2006;16(9):1131-4.

41. Holmberg D, Santoni G, Xie S, et al. Gastric bypass surgery in the treatment of gastro-oesophageal reflux symptoms. Aliment Pharmacol Ther. 2019;50(2):159-66.

42. Tahmassebi JF, Duggal MS, Malik-Kotru G, et al. Soft drinks and dental health: a review of the current literature. J Dent. 2006;34:2-11.

43. Fox B, Chen E, Suzo A, et al. Dietary and psych predictors of weight loss after gastric bypass. J Surg Res. 2015;197:283-90.

44. Meany G, Conceicao E, Mitchell JE. Binge eating, binge eating disorder and loss of control eating: effects on weight outcomes after bariatric surgery. Eur Eat Disord Rev. 2014;22:87-91.

45. Piva F, Pereira JT, Luz PB, et al. Caries progression as a risk factor for increase in the negative impact on OHRQOL-a longitudinal study. Clin Oral Investig. 2018;22(2):819-28.

46. Karlsson L, Carlsson J, Jenneborg K, et al. Perceived oral health in patients after bariatric surgery using oral health-related quality of life measures. Clin Exp Dent Res. 2018;4:230-40.

47. Locker D, Matear D, Stephens M, et al. Comparison of the GOHAI and OHIP-14 as measures of the oral health-related quality of life of the elderly. Community Dent Oral Epidemiol. 2001;29:373-81.
48. Larsson P, John MT, Hakeberg M, et al. General population norms of the Swedish short forms of oral health impact profile. J Oral Rehabil. 2014;41:275-81.

49. Wamala S, Merlo J, Boström G. Inequity in access to dental care services explains current socioeconomic disparities in oral health: the Swedish National Surveys of Public Health 2004-2005. J Epidemiol Community Health. 2006;60:1027-33.

50. Kochkodan J, Telem DA, Ghaferi AA. Physiologic and psychological gender differences in bariatric surgery. Surg Endosc. 2018;32: 1382-8.

51. Dao TT, LeResche L. Gender differences in pain. J Orofac Pain. 2000;14:169-95.

52. Leaper C, Friedman CK. The Socialization of Gender. In JE. Grusec \& PD. Hastings (Eds.), Handbook of socialization: Theory and research. New York, NY, US: Guilford Press; 2007. p. 561-87.

Publisher's Note Springer Nature remains neutral with regard to jurisdictional claims in published maps and institutional affiliations. 